\title{
Diversidade étnico-racial: uma experiência pedagógica em espaço não escolar
}

Ethnic-racial diversity: a pedagogical experience in non-school space

\author{
Diversidad étnico-racial: una experiencia pedagógica en el espacio no escolar
}

\author{
ESTEFANi CRUZ VIEIRA ${ }^{1}$; EVALdo RIBEIRo OLIVEIRA ${ }^{2}$ \\ UNIVERSIDADE DA INTEGRAÇÃo INTERNACIONAL DA LUSOFONIA AFRO-BRASILEIRA, UNILAB, REDENÇ̃̃o- \\ CE, BRASIL
}

\begin{abstract}
RESUMO
O presente artigo tem como objetivo apresentar uma experiência pedagógica desenvolvida a partir de uma atividade intitulada "Ser pedagoga (o) em espaços não escolares: vivências pedagógicas em espaços não escolares", da componente curricular "Pesquisa e Prática da Atuação do Pedagogo em Ambientes Não Escolares nos Países da Integração", do curso de Pedagogia da Universidade da Integração Internacional da Lusofonia Afro-Brasileira (UNILAB). Trata-se de uma oficina de contação de história, onde se buscou, por meio da história "Que Rei Sou Eu?", discutir sobre a diversidade étnico-racial que é composta nossa sociedade, refletir sobre a história dos povos africanos e sobre a temática afro-brasileira.

Palavras-chave: Prática Pedagógica. Espaço Não Escolar. Diversidade Étnico-Racial. Contação de História.
\end{abstract}

\begin{abstract}
This article aims to present a pedagogical experience developed in the activity entitled "Being a pedagogue in non-school spaces: pedagogical experiences in non-school spaces", from the curriculum component "Research and Practice of Pedagogic Practice in Non-School Environments in the Integration Countries", from the Pedagogy course at the University of International Integration of Afro-Brazilian Lusophony (UNILAB). It is a storytelling workshop, in which we sought through the story "What King Am I?", to discuss the ethnic-racial diversity that form our society, to reflect on the History of African peoples and about the Afro-Brazilian theme. Keywords: Pedagogical Practice. Non-School Space. Ethnic-Racial Diversity. Storytelling.
\end{abstract}

\section{RESUMEN}

Este artículo tiene como objetivo presentar una experiencia pedagógica desarrollada a partir de una actividad titulada "Ser un pedagogo en espacios no escolares: experiencias pedagógicas en espacios no escolares", del componente curricular "Investigación y práctica de la práctica pedagógica en entornos no escolares en los países de la integración", del curso de Pedagogía de la Universidad de Integración Internacional de la Lusofonía Afrobrasileña (UNILAB). Es un taller de narración de historias, donde, a través de la historia "¿Qué rey soy yo?", tratamos de discutir la diversidad étnico-racial que se compone nuestra sociedad, para reflexionar sobre la historia de los pueblos africanos y sobre el tema afrobrasileño.

Palabras clave: Práctica pedagógica. Espacio no Escolar. Diversidad Étnico-Racial. Derechos humanos.

\footnotetext{
${ }^{1}$ Graduanda do curso de Pedagogia da UNILAB, Instituto de Humanidades. E-mail: estefanivieira22@gmail.com ${ }^{2}$ Doutor em Educação e docente pertencente ao Instituto de Humanidades da UNILAB. E-mail: evaldo@unilab.edu.br
} 


\section{INTRODUÇÃOO}

Este trabalho foi construído a partir da proposta de atividade cuja temática era "Ser pedagoga (o) em espaços não escolares: vivências pedagógicas em espaços não escolares" apresentada na componente curricular "Pesquisa e Prática da Atuação do Pedagogo em Ambientes Não Escolares nos Países da Integração", do curso de Pedagogia da Universidade da Integração Internacional da Lusofonia Afro-Brasileira (UNILAB). A proposta do mesmo está dentro do campo de desenvolvimento de projetos educacionais, pois foi desenvolvido pensando em um espaço não escolar e teve como principal ferramenta de trabalho a contação de história.

A educação é um processo pelo qual ninguém escapa, não há uma forma, um modelo ou um lugar específico para que esta aconteça. Para muitos é impossível pensar educação fora dos muros da escola, pensando dessa forma excluímos todo e qualquer tipo de conhecimento adquirido pelo indivíduo em seu cotidiano, em sua vida social e familiar. Gonh (1998) em um de seus trabalhos sobre educação não-formal traz o conceito de educação associado ao conceito de cultura, isto quer dizer que a educação,

[...] é abordada enquanto forma de ensino/aprendizagem adquirida ao longo da vida dos cidadãos; pela leitura, interpretação e assimilação dos fatos, eventos e acontecimentos, que os indivíduos fazem, de forma isolada ou em contato com grupos e organizações (p. 516).

Pensando desta forma o pedagogo pode atuar em diversas áreas desenvolvendo projetos educacionais e culturais, portanto deve buscar uma educação livre de estereótipos, intolerância e preconceito.

O trabalho traz resultados de uma oficina onde se buscou por meio da contação de história, discutir sobre a diversidade étnico-racial que é composta nossa sociedade, refletir sobre a história dos povos africanos e sobre a temática afro-brasileira, com ênfase na valorização e positivação da identidade de negros (as) tendo em vista que esse processo de valorização e respeito pode favorecer a relação da sociedade com o negro(a) e do negro (a) consigo mesmo.

A história escolhida para a discussão foi a "Que Rei Sou Eu?"3, que traz a história de uma senhora negra que resolve contar sua história de vida a dois de seus netos. Na história a avó é descendente de reis da população de Zuru e traz alguns aspectos da vinda dos povos africanos a outros continentes, o sofrimento e tudo que tiveram de enfrentar durante este período, as dificuldades de sobrevivência, a pobreza, a falta de emprego, o racismo e negação desses povos. Traz ainda aspectos da atualidade em que mesmo em períodos distintos os povos negros sofrem com essa forma de tratamento e a necessidade de lutarmos por uma sociedade mais justa.

Nos tópicos a seguir traremos uma discussão sobre as relações étnico-raciais e sobre a contação de história como ferramenta para se trabalhar formação de personalidade e identidade. Em seguida a explanação do processo de planejamento e organização da oficina, e como se deu a realização da mesma.

\footnotetext{
${ }^{3}$ (OLIVEIRA, 2005, não publicado).
} 


\section{UMA BREVE DISCUSSÃO SOBRE A DIVERSIDADE ÉTNICO-RACIAL E A CONTAÇÃO DE HISTÓRIA}

O Brasil é um país conhecido pela diversidade de povos, entre eles, indígenas, africanos e europeus, que o compõem e pela sua diversidade étnica e cultural, com predominância da população negra, que corresponde a cinquenta e quatro por cento da população, de acordo com o IBGE (2016). No âmbito educacional trabalhar com a diversidade étnico-racial pode desenvolver e favorecer valores e atitudes baseadas no respeito às diferenças melhorando assim as relações raciais, explorar esta temática pode não só nos fazer refletir sobre as nossas concepções sobre os povos que fizeram parte da construção da nossa sociedade, mas também nos permite conhecer sua cultura e desfazer estereótipos sobre os mesmos.

Cabe lembrar que o Brasil passou por um processo de colonização e que a educação brasileira teve (e ainda tem) seu sistema e currículos construídos com base em uma visão eurocêntrica, desta forma deixando de fora outras culturas existentes na sociedade brasileira, tornando-se algo distante da nossa realidade e abrindo espaço para discriminações a determinados grupos sociais. A realidade educacional brasileira ainda enfrenta muitos desafios, porém algumas lutas por modificações desta realidade vêm acontecendo, como por exemplo, a luta do Movimento Negro desde o século XX. De acordo com Oliveira (2008):

[...] o Movimento Negro surge e se constitui dentro do contexto nacional, que se articula na chamada "democracia racial", permeada pela "ideologia do branqueamento". A referida "democracia racial" difunde a idéia de que as relações dos diferentes grupos étnico-raciais são harmoniosas, particularmente entre negros e brancos (p. 31).

O Movimento Negro priorizou as transformações de realidades, na busca por respeito, reconhecimento e valorização da população negra, como afirma Oliveira (2008):

[...] o Movimento Negro compreende que uma das suas demandas para modificar a sociedade brasileira, objetivando a equidade entre os grupos étnicos, é a educação. Desta forma, inicia-se um processo de denúncia do racismo na educação brasileira e a proposição de ações pedagógicas para combater a marginalização física e simbólica do povo negro na educação. Sendo assim, o Movimento Negro apresenta demandas por uma educação que respeite, reconheça e valorize a população negra (p. 32).

Resultantes das lutas do Movimento Negro, o Parecer CNE/CP 003/2004, introduz os artigos 26-A e 79-B na Lei 9.394/96 (Lei de Diretrizes e Bases). Também são introduzidas as Diretrizes Curriculares Nacionais para a Educação das Relações Étnico-Raciais e Para o Ensino de História e Cultura Afro-Brasileira e Africana que trazem garantia para implementação de projetos educacionais que valorizem a cultura negra e que também possibilitem condições para o conhecimento de culturas e histórias dos povos que compõem a sociedade brasileira. De acordo com o Parecer CNE/CP 003/2004 "[...] a educação das relações étnico-raciais impõe aprendizagens entre brancos e negros, trocas de conhecimentos, quebra de desconfianças, projeto conjunto para construção de uma sociedade justa, igual, equânime" (BRASIL, 2004, p. 14).

Para que esta educação das relações étnico-raciais seja possível é necessário que o currículo seja preparado de acordo com os documentos citados, com o objetivo de valorizar diversidades e identidades dos sujeitos envolvidos nas discussões em um 
mesmo ambiente de aprendizagem, ou seja, para promover uma educação das relações étnico-raciais é necessário romper com as amarras do etnocentrismo. Não são mudanças simples ou fáceis, pois exige a modificação de práticas pedagógicas cristalizadas. Conceição (2006) afirma que, questões relativas à educação das relações étnico-raciais para alguns educadores são delicadas, diz ela:

\begin{abstract}
Abordar em sala de aula questões relativas à educação das relações étnicoraciais, para alguns educadores, é muito delicado, pois implica rever valores éticos, pessoais e profissionais. É, por vezes, se descobrir racista, preconceituoso, discriminador e que, muitas vezes, as atitudes diante destas situações são de silenciamento, por não ter a sensibilidade necessária para identificá-las ou por não saber como agir (p. 24).
\end{abstract}

O desafio de promover a educação das relações étnico-raciais não está restrito apenas aos educadores em contexto de sala de aula, mas envolve todos aqueles que compõem o estabelecimento de ensino e os produtores de conteúdo, como escritores e editoras. Pois, para que haja um trabalho de sensibilização e reconhecimento do outro é necessário que se tenha um referencial teórico bem elaborado que possibilite pensamentos e atitudes antidiscriminatórios. Existem diversos materiais produzidos que podem ser utilizados para este fim, músicas, filmes, livros, imagens, revistas, histórias. É importante considerar que o momento de escolha do material a ser utilizado, necessita de uma análise cuidadosa de seu conteúdo, que mensagem irá transmitir e se pode possibilitar uma mudança de pensamento e atitude.

Tomar o cuidado na escolha do material e no que a mensagem passa é pensar no outro, em quem está ouvindo, e na forma como as relações entre os indivíduos se darão a partir do que está se propondo, pois, pela socialização de conhecimentos o indivíduo aprende o que é correto ou incorreto e após esta análise modificará seu comportamento no meio social em que está inserido. A partir deste momento traremos as questões relacionadas à temática da contação de histórias e sua contribuição nesse processo da educação das relações étnico-raciais.

A contação de história é uma excelente ferramenta para a educação, pois, estimula a criatividade, a oralidade, a imaginação, o interesse pela leitura. As histórias podem contribuir para criação de situações desafiadoras como no caso das discussões feitas em torno da temática da diversidade étnico-racial.

Sobre a contação de história Souza e Bernardino (2011) afirmam:

De acordo com vários estudiosos a contação de histórias é um valioso
auxiliar na prática pedagógica de professores da educação infantil e anos
iniciais do ensino fundamental. As narrativas estimulam a criatividade e a
imaginação, a oralidade, facilitam o aprendizado, desenvolvem as linguagens
oral, escrita e visual, incentivam o prazer pela leitura, promovem o
movimento global e fino, trabalham o senso crítico, as brincadeiras de faz-de-
conta, valores e conceitos, colaboram na formação da personalidade da
criança, propiciam o envolvimento social e afetivo e exploram a cultura e a
diversidade (p. 236).

Desta forma pode favorecer de maneira significativa, pois através da escuta de histórias estimula-se a imaginação e sem perceber o ouvinte desenvolve o seu conhecimento sobre o mundo e sobre o meio em que vive. Araújo e Morais (2014) mostram a importância de envolver e estimular a criança a participar da história, fazendo com que ela se sinta parte do que está sendo narrado, dizem eles: 
[...], o/a professor/a, ao contar uma história, deve envolver a criança e fazê-la identificar-se com os personagens. Pois, ao interagir com a história, a criança passa a despertar emoções como se estivesse vivendo o que ali lhe é narrado, permitindo que, através da imaginação, exercite a capacidade de resolução de situações cotidianas (p. 5).

Os autores trazem a literatura infantil ligada ao ato de contar histórias, onde por meio dela torna- se possível a socialização e transmissão de valores, mas do que isto,

[...] a literatura infantil atrelada ao ato de contar história, na educação infantil, funciona como importantes meio de socialização, de construção da identidade, de transmissão de valores morais e culturais e na formulação de conceitos e no desenvolvimento cognitivo. Daí a relevância em se trabalhar literatura infantil afro-brasileira no ambiente educacional, bem como no círculo familiar e outros espaços (ARAÚJO; MORAIS, 2014, p. 6-7).

O termo "construção" utilizado pelos autores na citação acima quando se referem à identidade, deixa claro que a identidade não é algo pronto, é algo que se constrói ao longo da vida de acordo com os referenciais que lhe são apresentados, como por exemplo, brinquedos e personagens de histórias.

Trabalhar com a contação de história para discutir a diversidade étnico-racial contribui para a construção ou reconstrução de conhecimentos e possibilita ao indivíduo uma mudança de comportamento e respeito com as diferenças existentes entre nós e possibilita a quebra de estereótipos que levam ao preconceito e à discriminação. Se realmente pensamos em mudar o pensamento eurocêntrico da sociedade brasileira, precisamos pensar e desenvolver abordagens pedagógicas voltadas para a diversidade étnico-racial e cultural brasileira em todas as modalidades de ensino.

\section{PlaneJAMENTO E ORGANIZAÇÃo: O PROCESSO DE REALIZAÇÃo}

Apresentada a proposta de contação de história, foi iniciada a organização com a preparação do material necessário para utilização nas atividades, a ideia era que a contação da história "Que Rei Sou Eu?" fosse realizada com a utilização de fantoches, confeccionados em E.V.A, em seguida, foi preparado um mural, com pano, para manusear os fantoches, depois foram colocados tecidos no chão, para que as crianças pudessem se sentir confortáveis no momento da contação da história, e por fim, organizou-se os materiais de pintura para confecção dos desenhos: lápis de cor, lápis de escrever, papel ofício, canetinhas, giz de cera. A realização da contação da história ocorreu no dia 24 de março de 2019, em uma igreja evangélica localizada na zona rural da cidade de Acarape-CE.

Primeiramente realizou-se a dinâmica de apresentação "Eu sou... E você, quem é?" ", que consiste basicamente em se apresentar falando seu nome e passando a vez para a pessoa ao seu lado, por exemplo, "Eu sou Joana. E você, quem é?". Desta forma foi feito e todas as crianças se apresentaram. O objetivo era conhecer as pessoas participantes.

Em seguida, para dar início à discussão sobre a diversidade étnico-racial existente em nossa sociedade conversamos sobre os diversos tons de pele, a partir do lápis de cor rosa claro, conhecido de forma errônea como "lápis cor de pele", onde foi utilizada uma caixa de giz de cera e algumas imagens de pessoas negras (em seus diversos tons) e

\footnotetext{
${ }^{4}$ Disponível em: 〈https://professoremsala.com.br/5-dinamicas-excelentes-para-o-primeiro-dia-de-aula/〉.
} 
brancas, para que as crianças pudessem compreender que somos diferentes e que independente de nossas características físicas e culturais devemos respeitar uns aos outros.

Foi apresentada a elas uma caixa de giz de cera e aos poucos retirando os gizes e perguntando qual era a cor que eles viam, quando chegou a vez do lápis de cor rosa claro, como esperado, elas responderam "cor de pele". Neste momento foi questionado "cor de pele?" e rapidamente uma delas falou baixinho "rosa claro", mas nem todas as crianças ouviram. Como o objetivo era, a partir das respostas, desenvolver a discussão, foi questionado: "Mas que cor de pele?" houve um silêncio.

Continuando a atividade, com algumas imagens de pessoas com diversos tons de pele, negras em seus diversos tons, do mais claro aos mais escuros e de pessoas brancas, íamos apresentamos a imagem e questionando se a cor era igual ao lápis "cor de rosa claro" e as respostas quando eram pessoas negras era não e quando eram brancas sim.

Em seguida apresentamos a imagem de uma mulher negra, de pele preta, apresentando o seguinte questionamento: "Que cor se chama essa aqui?". Rapidamente um menino responde "preto", consequentemente é apresentando o lápis preto, com o objetivo de comparar a cor da pessoa da imagem com a cor do lápis, lançando novamente a interpelação: "É preto?". Surgem comentários como "moreno", "marrom". Destacamos que é uma pessoa negra, sendo que os/as negros/as possuem diversos tons de pele, sendo uns mais claros, outros mais escuros, porém todos negros e negras.

Novamente com as imagens das pessoas com o tom de pele diferentes, foi questionado por fim; "podemos chamar só esse lápis de 'cor de pele'?". Um sonoro "não" é apresentado. Ao questionarmos o porquê é apresentado como resposta: "Por que existem vários tons de pele", mas ao serem perguntados sobre o nome do lápis cor de rosa, inicialmente como lápis cor de pele, o silêncio predomina. Então, ensinamos que a cor correta do lápis é rosa claro.

Terminado este momento e com intuito de mostrar a diversidade racial, foi solicitado que, em círculo, aproximando os nossos braços, para que vejam as cores de pele dos colegas, as diferentes texturas de cabelos, as diferentes cores de olhos, formatos de nariz, destacando as nossas diferenças e semelhanças, com o intuito de destacar que somos todos diferentes, que é necessário respeitar tais diversidades.

Finalizada esta atividade, iniciamos a contação da história "Que Rei Sou Eu?" com a utilização de três fantoches, dois de pele escura e um de pele clara. A contação foi realizada buscando sempre introduzir o público através do diálogo na história, com o objetivo de fazê-los se sentirem parte dela.

Finalizada a história, iniciou-se a segunda discussão, trazendo os aspectos da história questionando inicialmente sobre os personagens: "Como eles eram?". Um silêncio predominou, então para facilitar a discussão, exploramos os aspectos físicos dos personagens: "Qual a cor dos olhos?". Eles responderam com um sonoro "preto", "E do cabelo?", rapidamente respondem: "Preto", "E a cor da pele?". Uma das crianças responde: "Dois morenos e um branco". "O que aconteceu com vovó Mina?", uma das crianças responde: "Ela contou tudo para a Carol". Questionamos: "Mas o que ela contou?", como resposta obtivemos: "De onde ela veio". Por fim questionamos: "Porque o Miguel saiu gritando para todo mundo que era rei?", uma das crianças responde: "Porque os pais dele era".

Conforme eles iam respondendo explicávamos o que eles não compreendiam, de onde veio a avó, que na história ela veio do Reino de Zuru ${ }^{5}$. Questionamos: "O que é

\footnotetext{
${ }^{5}$ Nome fictício utilizado na história para fazer alusão aos reinos africanos.
} 
Zuru?", sem resposta, é explicado que é um reino africano, quem tem relação com o Brasil, devido à escravização de seres humanos.

Outros questionamentos foram realizados, entre eles, porque os personagens eram reis ou descendentes de reis, o que eram descendentes. Realizamos as devidas explicações e finalizamos ressaltando a importância das características físicas, que são importantes para cada um e uma se constituir enquanto pessoa, por isto, de forma lúdica, questionamos se podem xingar o colega devido a cor da pele dele (a) ou devido a outros elementos étnico-raciais, como cabelo. Mesmo ouvindo o "não" como resposta, foi ressaltado que, o preconceito ainda existe e por isto, a luta por respeito e igualdade racial.

Finalizamos este momento de conversa distribuindo materiais para a confecção de desenhos e alguns moldes em branco para a confecção de coroas de reis e rainhas.

\section{CONSIDERAÇÕES FINAIS}

Durante a realização da atividade foi perceptível o entusiasmo das crianças com o que estava acontecendo, a participação delas foi algo surpreendente, pois, mesmo estando com pessoas que não fazem parte de seus contextos, distantes do seu convívio, não se sentiram intimidadas ou tímidas, participaram o tempo inteiro, fizeram perguntas, responderam aos questionamentos propostos.

A escolha da história "Que Rei Sou Eu?" possibilitou às crianças uma desconstrução dos preconceitos existentes na nossa sociedade, possibilitou a discussão de questões relevantes para a formação de um cidadão que vive em uma sociedade tão plural como é a nossa. Isso nos mostra o quão importante é a contação de história e que, com as discussões feitas a partir dela, é possível que haja uma mudança de pensamento, uma quebra de preconceitos, fortalecendo o respeito e valorização às diferenças, enfatizando uma cultura de paz.

É gratificante perceber que através desta prática educativa mudanças se tornaram possíveis como na discussão em torno do "lápis cor de pele", que possibilita a todos a desconstrução de fatores negativos com relação ao negro. Os participantes contribuíram, compreenderam e desenvolveram habilidades para a desconstrução de preconceitos.

É importante destacar que essa prática educativa não foi realizada em uma escola, nos mostrando que a educação perpassa os muros institucionais e que em todo lugar se aprende.

Outro elemento importante desta oficina foi o local da realização, uma igreja evangélica, lugar que também deve acontecer a educação das relações étnico-raciais, mas não apenas a partir de uma visão religiosa "que somos todos iguais perante Deus", mas sim, problematizando as mazelas que as diferenças raciais têm produzido, como o racismo. Além disso, ao realizar tal atividade neste espaço, não abalamos, questionamos ou criticamos a fé de ninguém, mas apresentamos, de forma lúdica, uma realidade social, o racismo, mas do que isto, trouxemos conhecimentos sobre povos, que tem reis e rainhas, mas não fica na Europa, e sim, na África, que os povos negros são descendentes destes reis e rainhas, e não de escravizados. 


\section{REFERÊNCIAS}

ARAÚJO, J. A.; MORAIS, R. S. A relevância em se trabalhar a literatura infantil afro-brasileira na educação infantil. Africanias.com, v. 5, p. 1-17, 2014.

BRASIL. Conselho Nacional de Educação. Parecer CNE/CP n. 003/2004 de 10 de Março de 2004. Diretrizes Curriculares Nacionais para a Educação das Relações Étnico-Raciais e para o Ensino de História e Cultura Afrobrasileira e Africana. Diário Oficial da União, Brasília, DF, 19 maio 2004.

CONCEIÇÃO, R. As relações étnico-raciais, história e cultura afro-brasileira na educação infantil. In: BRASIL. Currículo, relações raciais e cultura afro-brasileira - boletim 20. Brasília: Secretaria de Educação a Distância, 2006. p. 22-28.

GOHN, M. G. Educação não formal: um novo campo de atuação. Ensaio: Avaliação e Políticas Públicas em Educação, v. 6, n. 21, p. 511-526, out./dez.1998.

IBGE. Pesquisa nacional por amostra de domicílios: síntese de indicadores 2015. Rio de Janeiro: IBGE, 2016. Disponível em: <https://biblioteca.ibge.gov.br/visualizacao/livros/liv98887.pdf>. Acesso em: 30 ago. 2019.

OLIVEIRA, E. R. Narrativas de Tereza Santos - Contribuições para a Educação das Relações ÉtnicoRaciais. 2008. 145 p. Dissertação (Mestrado em Educação) - Centro de Educação e Ciências Humanas, Universidade Federal de São Carlos, São Carlos, 2008.

OLIVEIRA, E. R. Que rei sou eu? 2005. (Não publicado).

SOUZA, L. O.; BERNARDINO, A. D. A contação de histórias como estratégia pedagógica na educação infantil e ensino fundamental. Revista de Educação Educere et Educare, v. 6, n. 12, p. 235-249, jul./dez. 2011.

Recebido em: 29 jul. 2019.

Aprovado em: 30 ago. 2019. 